\title{
THE SPEED OF SOUND PULSES IN PIPES.
}

By Arthur L. Foley.

SYNOPSIS.

\begin{abstract}
Speed of sound pulses in short tubes placed near a spark source; measured by the photographic method. By a modification of this method, an instantaneous photograph was obtained of a sound pulse, part of which had come through a tube, while another part had come through free air. In this way the effect of short tubes of various sizes was determined when their near ends were from one to five centimeters from the spark. Two photographs are reproduced which show that in some cases the pulse may travel faster through a short tube than in free air, and faster through the smaller of two tubes than through the larger. The speed through a tube was found to depend chiefly on the intensity of the pulse as it entered the tube, and this was true even when the motion of the air as a body was prevented by a thin collodion membrane stretched across one end of the tube. The mean speed was less the longer the tube.

Speed of sound in tubes; historical summary with a discussion of the Kirchoff formula and a table of the results obtained by various methods for tubes of various sizes and materials, and for various pitches.
\end{abstract}

THE speed of sound in pipes has been experimentally determined directly by measuring the time required for a sound (I) to pass from one to the other end of a pipe; (2) to return to the source after reflection from the closed distant end; (3) to pass through a $U$ tube and return to the source. Of the several indirect methods one may name the calculation of sound speed from the length and frequency of an organ pipe, or the change in length necessary to restore the pitch of a pipe sounding a harmonic of known frequency. The so-called resonance tube method is practically the same as the organ pipe method except that the air column is thrown into vibration by means of a tuning fork or some other source of known frequency. The Kundt's tube has been used with the familiar dust figures and it has been modified to permit the location of the nodal and anti-nodal points by using branch tubes to the ear, to a manometric flame, or to a capsule covered with a thin membrane carrying a tiny mirror. A further modification consists in using a double Kundt's tube, a tube on each end of a vibrating rod which is rubbed at its middle point. Of the several interference methods Quincke's double tube method is the simplest. A sound passing through a tube divides at a $\mathrm{Y}$ and is reunited at a second $\mathrm{Y}$ after the two parts have traveled through branch tubes of unequal length, adjusted to give either constructive or destructive interference as desired. 
In I 862-63 Regnault, ${ }^{1}$ in Paris, made an elaborate series of experiments on the speed of sound in newly laid water pipes. As sources of sound he used a pistol, explosions and musical instruments. Both ends of the pipes were closed and the sound was produced at one end. The wave passed back and forth through the pipe many times, its time of arrival at the end being recorded on a chronograph drum by a stylus operated electrically when the sound wave impinged on a thin membrane and closed an electric circuit. From these experiments Regnault concluded that the speed of sound is greater in large pipes than in small ones; that the speed tends to a lower limit as the distance from the source increases and therefore as the intensity of the sound decreases; and that the limiting speed is the same for all sources. Rink objected to Regnault's conclusions on the ground that the first few coursings of the sound through the pipes was affected by the motion of the air in a body, caused by the explosion. Omitting the first two passages Rink ${ }^{2}$ concluded from Regnault's experiments that neither the distance from the source nor the charge of powder used had any effect on the speed of the wave, in other words, that the speed of sound is independent of its intensity. On this point, however, most subsequent experimenters agree with the conclusion of Regnault. They agree also that the speed of sound in a pipe is a function of its diameter. They differ from Regnault by finding that the speed is a function of pitch, being greater for notes of high pitch.

In Table I. the writer has tabulated a few of the results obtained by various experimenters. It will be observed that the speed was found to depend on the material of the walls of the tube, on the diameter of the tube, and on the pitch of the sound. Most of the work referred to in the table was done for the purpose of arriving at an equation connecting these variables. The problem was attacked theoretically by both Helmholtz ${ }^{3}$ and Kirchoff, ${ }^{4}$ who arrived at equations reducible to the form

$$
u=v\left(\mathrm{I}-\frac{c}{2 r \sqrt{2 \pi n}}\right),
$$

where $u$ is the speed of sound of frequency $n$ in a pipe of radius $r, v$ being the speed in free air. According to Helmholtz $c$ is the viscosity of the gas while Kirchoff makes it depend on heat conduction between the gas and the wall of the tube. Kayser ${ }^{5}$ found that the equation holds

\footnotetext{
1 V. Regnault, Mem. de l'Acad. Paris, 37, I., 3, I868; Comptes Rendus, 66, 209, I868; Phil. Mag., S. 4, V. 35, p. I6I, 1868.

2 H. J. Rink, Pogg. Ann., V. I49, p. 533, 1873.

${ }^{3}$ H. v. Helmholtz, Wissench., Abhandl., V. I, p. 338, 1882.

4 G. Kirchoff, Pogg. Ann., V. 134, p. 77, 1868.

${ }^{5}$ H. Kayser, Wied. Ann., V. 2, p. 218 , 1877.
} 
TABLE I.

Speed of Sound Waves in Pipes.

\begin{tabular}{|c|c|c|c|c|c|c|}
\hline Observer. & Method Used. & Source of Sound. & $\begin{array}{l}\text { Kind of } \\
\text { Pipe. }\end{array}$ & Frequency. & $\begin{array}{l}\text { Diameter of } \\
\text { Pipe, cm. }\end{array}$ & $\begin{array}{l}\text { Speed, } \\
\text { cm./sec. }\end{array}$ \\
\hline $\begin{array}{c}\text { Wertheim, } 1 \\
1844\end{array}$ & Organ pipe & & $\begin{array}{l}\text { Brass } \\
\text { "“ } \\
\text { Glass } \\
\text { Brass }\end{array}$ & & $\begin{array}{l}1.0 \\
2.0 \\
2.0 \\
4.0\end{array}$ & $\begin{array}{l}329.12 \\
330.11 \\
330.23 \\
332.10\end{array}$ \\
\hline $\begin{array}{c}\text { Le Roux, }{ }^{2} \\
1867\end{array}$ & $\begin{array}{l}\text { Modified Reg- } \\
\text { nault method }\end{array}$ & $\begin{array}{l}\text { Tap on mem- } \\
\text { bra } n \text { e over } \\
\text { end of } U \text { tube }\end{array}$ & & & 7.0 & 330.66 \\
\hline $\begin{array}{c}\text { Kundt, }{ }^{3} \\
1868\end{array}$ & $\begin{array}{l}\text { Double } \\
\text { Kundt's tube, } \\
\text { dust figures. }\end{array}$ & $\begin{array}{l}\text { Longitudinal } \\
\text { vibrations of } \\
\text { a glass tube. }\end{array}$ & $\begin{array}{c}\text { Glass } \\
\text { “" } \\
\text { “ } \\
\text { ، } \\
\text { “ } \\
\text { ، }\end{array}$ & $\begin{array}{c}1850 \\
، \\
، \\
، \\
5550 \\
، \\
،\end{array}$ & $\begin{array}{l}0.35 \\
0.65 \\
1.30 \\
5.50 \\
0.65 \\
1.30 \\
5.50\end{array}$ & $\begin{array}{l}305.42 \\
323.00 \\
329.47 \\
332.80 \\
328.14 \\
330.87 \\
332.80\end{array}$ \\
\hline $\begin{array}{c}\text { Regnault, }^{4} \\
1868\end{array}$ & See text above & $\begin{array}{l}\text { Pistol, charge } \\
\text { of } .4 \mathrm{gm} \text {. } \\
\text { powder }\end{array}$ & $\begin{array}{c}\text { Iron } \\
\text { " } \\
\text { " } \\
\text { " } \\
\text { " }\end{array}$ & & $\begin{array}{c}10.8 \\
10.8 \\
33.0 \\
33.0 \\
110 \\
110\end{array}$ & $\begin{array}{l}330.99 \\
326.66 \\
331.64 \\
328.96 \\
334.16 \\
330.52\end{array}$ \\
\hline $\begin{array}{c}\text { Seebeck, } \\
1870\end{array}$ & $\begin{array}{l}\text { Resonance } \\
\text { tube, sliding } \\
\text { piston lateral } \\
\text { ear tube to } \\
\text { locate nodes. }\end{array}$ & Tuning fork & $\begin{array}{c}\text { Glass } \\
\text { "، } \\
\text { "، } \\
\text { " } \\
\text { " }\end{array}$ & $\begin{array}{l}320 \\
320 \\
320 \\
512 \\
512 \\
512\end{array}$ & $\begin{array}{l}0.34 \\
0.90 \\
1.75 \\
0.34 \\
0.90 \\
1.75\end{array}$ & $\begin{array}{l}317.26 \\
328.02 \\
329.24 \\
322.98 \\
328.44 \\
330.92\end{array}$ \\
\hline $\begin{array}{c}\text { Blaikley, }{ }^{6} \\
1879\end{array}$ & $\begin{array}{l}\text { Closed } \\
\text { resonance } \\
\text { tube, length } \\
\text { adjusted to } \\
\text { pitch of open } \\
\text { tube. }\end{array}$ & $\begin{array}{l}\text { Sound pro- } \\
\text { duced by } \\
\text { blowing } \\
\text { across end of } \\
\text { tube itself. }\end{array}$ & $\begin{array}{c}\text { Brass } \\
\text { " } \\
\text { " }\end{array}$ & $\begin{array}{l}506.8 \\
506.8 \\
506.8\end{array}$ & $\begin{array}{l}1.10 \\
2.65 \\
5.28\end{array}$ & $\begin{array}{l}323.73 \\
328.28 \\
329.48\end{array}$ \\
\hline $\begin{array}{c}\text { Blaikley, }^{7} \\
1883\end{array}$ & $\begin{array}{l}\text { Special form of } \\
\text { organ pipe. }\end{array}$ & $\begin{array}{l}\text { Organ pipe } \\
\text { blown with } \\
\text { constant air } \\
\text { pressure. }\end{array}$ & $\begin{array}{c}\text { Brass } \\
\text { " } \\
\text { " } \\
\text { ", }\end{array}$ & $\begin{array}{l}256 \\
256 \\
256 \\
256 \\
256\end{array}$ & $\begin{array}{l}1.17 \\
1.95 \\
3.25 \\
5.41 \\
8.82\end{array}$ & $\begin{array}{l}324.56 \\
326.90 \\
328.78 \\
329.72 \\
330.13\end{array}$ \\
\hline
\end{tabular}

1 Pogg. Ann., Bd. 77, s. 427, I 844.

${ }^{2}$ LeRoux, Ann. Chim. Phys., (4), r2, 345, x867.

${ }^{3}$ A. Kundt, Pogg. Ann., Bd. 135, s. 333 u. 527, I868; Phil. Mag., V. 36, p. 4, I868.

4 V. Regnault, loc. cit.

5 A. Seebeck, Pogg. Ann., Vol. r39, p. r04, 1870; Ann. Chim. Phys., s. 4, Vol. I5, p. 487 I870; Abstract, Phil. Mag., s. 4, Vol. 40, p. 23I, I87o.

${ }^{6}$ D. J. Blaikley, Phil. Mag., V. 7, p. 343, 1879.

7 D. J. Blaikley, Phil. Mag., V. I6, p. 447 , I883. 
TABLE I (Continued)

\begin{tabular}{|c|c|c|c|c|c|c|}
\hline Observer. & Method Used. & Source of Sound. & $\begin{array}{c}\text { Kind of } \\
\text { Pipe. }\end{array}$ & Frequency. & $\left|\begin{array}{c}\text { Diameter of } \\
\text { Pipe, cm. }\end{array}\right|$ & $\begin{array}{c}\text { Speed, } \\
\text { cm./sec. }\end{array}$ \\
\hline $\begin{array}{r}\text { Law, }{ }^{1} \\
1894\end{array}$ & $\begin{array}{l}\text { Resonance } \\
\text { tube, branch } \\
\text { tube to ear. }\end{array}$ & Tuning fork. & $\begin{array}{c}\text { Glass } \\
\text { “" } \\
\text { “" } \\
\text { “" } \\
\text { “" } \\
\text { " } \\
\text { “ }\end{array}$ & $\begin{array}{r}256 \\
512 \\
1023 \\
256 \\
512 \\
1023 \\
256 \\
512 \\
1023\end{array}$ & $\begin{array}{l}0.93 \\
0.93 \\
0.93 \\
1.71 \\
1.71 \\
1.71 \\
2.80 \\
2.80 \\
2.80\end{array}$ & $\begin{array}{l}320.60 \\
323.60 \\
325.29 \\
325.24 \\
326.70 \\
327.80 \\
327.29 \\
328.33 \\
328.68\end{array}$ \\
\hline $\begin{array}{c}\text { Stevens, }{ }^{2} \\
1902\end{array}$ & $\begin{array}{l}\text { Quincke's } \\
\text { Interference } \\
\text { method. }\end{array}$ & Tuning fork. & $\begin{array}{c}\text { Porcelain } \\
" ” \\
\text { Iron }\end{array}$ & $\begin{array}{l}600 \\
508 \\
508\end{array}$ & $\begin{array}{l}4.00 \\
4.00 \\
4.00\end{array}$ & $\begin{array}{l}331.29 \\
331.54 \\
330.95\end{array}$ \\
\hline $\begin{array}{c}\text { Müller, }{ }^{3} \\
1903\end{array}$ & $\begin{array}{l}\text { Resonance } \\
\text { tube. } \\
\text { Dust figures. }\end{array}$ & $\begin{array}{l}\text { Tuning fork } \\
\text { electrically } \\
\text { driven. }\end{array}$ & Glass & $\begin{array}{r}903 \\
903 \\
903 \\
2482 \\
2482 \\
2482\end{array}$ & $\begin{array}{l}0.37 \\
0.68 \\
1.55 \\
0.37 \\
0.68 \\
1.55\end{array}$ & $\begin{array}{l}317.2 \\
322.9 \\
327.3 \\
323.0 \\
325.4 \\
330.2\end{array}$ \\
\hline $\begin{array}{c}\text { Schulze, }{ }^{4} \\
1904\end{array}$ & $\begin{array}{l}\text { Quincke's } \\
\text { Interference } \\
\text { tubes. }\end{array}$ & & $\begin{array}{c}\text { Glass } \\
\text { “ } \\
، \\
\text { Brass } \\
\text { “ } \\
\text { ، } \\
\text { "“ } \\
\text { Rubber }\end{array}$ & $\begin{array}{l}384 \\
384 \\
512 \\
512 \\
384 \\
384 \\
512 \\
512 \\
512\end{array}$ & $\begin{array}{l}0.101 \\
0.151 \\
0.101 \\
0.101 \\
0.099 \\
0.148 \\
0.099 \\
0.148 \\
0.150\end{array}$ & $\begin{array}{l}258 \\
282 \\
265 \\
290 \\
189 \\
230 \\
208 \\
253 \\
195\end{array}$ \\
\hline
\end{tabular}

if $c$ is placed equal to 0.0235 instead of the theoretical value 0.00588 . Schneebeli ${ }^{5}$ and Seebeck ${ }^{6}$ found the equation true only so far as it connects speed and pipe diameter, and that the decrease in speed is inversely proportional to the square root of the cube of the frequency. According to Müller ${ }^{7}$ the Helmholtz equation has no general validity. According to Schulze ${ }^{8}$ the "constant" $c$ was found to range between 0.0075 and 0.025 , depending on the diameter and nature of the tube.

${ }^{1}$ J. W. Low, Ann. der Phys., V. 52, p. 64r, 1894.

2 E. H. Stevens, Ann. der Phys., V. 7, p. $285,1902$.

${ }^{3}$ J. Müller, Ann. der Phys., V. II, p. 33I, r9o3.

4 F. A. Schulze, Ann. der Phys., V. 13, p. I060, I904.

5 H. Schneebeli, Pogg. Ann., V. I36, p. 296, 1869.

${ }^{6}$ Loc. cit.

${ }^{7}$ Loc. cit.

${ }^{8}$ Loc. cit. 
Sturm $^{1}$ found that the Kirchoff formula was not valid for different tubes and frequencies while the results obtained by Wertheim ${ }^{2}$ and by Blaikley ${ }^{3}$ support the theoretical equation. Thus it will be seen that there is no consensus of opinion on the question of the speed of sound waves in tubes and the theoretical equations connecting speed, diameter and pitch have not been verified. It will be noted, further, that the speed of sound waves in tubes of small diameter has been found in every instance by the Kundt's tube or some resonance tube method. The conditions obtaining for a stationary wave are so different from those in the case of a traveling wave that the speed calculated for the former is not necessarily the true speed of the latter. The direct methods of Regnault and others have been applied to large tubes only, and they are open to the objection that the wave recording devices are subject to a time lag which depends on the intensity and type of the wave, both of which vary with the distance from the source. To avoid these various sources of error it occurred to the writer to photograph simultaneously two portions of the same wave, one part traveling in free air, the other passing through a tube, and then compare their speeds directly.

The general plan of the experiment is shown in Fig. I, in which the light spark, the sound producing spark and the sound wave are shown in section while the tubes $T_{1}, T_{2}, T_{3}, T_{4}$, through which the sound passed, and the dry plate $P$, are shown in perspective. $B, B^{\prime}$ are brass rods, bent as shown, and tipped with platinum points to form a sound spark gap about $2.5 \mathrm{~cm}$. long. To prevent light from this spark from falling on the photographic plate a hard rubber disk or button was placed on each terminal of the gap. A spark passing between the platinum points generates a cylindrical wave with hemispherical ends, shown in cross section at $W W^{\prime}$. Suppose, while the wave is in this position, that a spark occurs at the light gap. The light rays above $x$ and below $z$ are practically unaffected. The entire plate is therefore about equally illuminated, except for the region lying between where the rays $x$ and $z$ strike the plate. If the wave is a condensation the ray $Y$ is bent toward the center. Remembering that the wave is cylindrical we should have on the plate a dark ring shadow $D R$ outside and a light ring $L R$ inside, both concentric with $D$, the shadow of the rubber disk. If the wave were a rarefaction the dark ring would be on the inside. This fact enables us to know whether or not in a given case, there is any change of phase on reflection, etc. $E E^{\prime}$ are terminals of an electric machine capable of yielding sparks $20 \mathrm{~cm}$. long. Sparks from these terminals

1 J. Sturm, Ann. d. Phys., V. I4, p. 822, 1904.

2 Loc. cit.

${ }^{3}$ Loc. cit. 
pass across the gaps $G G^{\prime}$ and through the sound gap and light gap, which are in series. The spark in the latter is made to occur a little later than the one producing the sound wave, by a capacity $K$. The reader is referred to an earlier article ${ }^{1}$ for fuller details of the method. I shall describe here only what is special for this investigation.

Concentric with the sound gap is a half ring cut from a piece of brass tubing $3 \mathrm{~cm}$. in diameter and $5 \mathrm{~cm}$. long. The half ring is supported by a rod $R$ and itself supports radially four brass tubes $T_{1}, T_{2}, T_{3}$ and $T_{4}$ respectively $0.25 \mathrm{~cm} ., 0.48 \mathrm{~cm} ., 0.8 \mathrm{~cm}$., and $I .15 \mathrm{~cm}$. in internal diameter, each $2.5 \mathrm{~cm}$. long. The shadow of the half ring and the four tubes is shown on the plate. The supporting rods $B, B^{\prime}$ and $R$ were arranged in a line with the light gap so as to show but one shadow on the plate. With this arrangement one half the sound wave travels in free air. The other half is cut off except for the portions which enter the tubes.

Fig. 2 of Plate I. shows the result, when the sound wave was what I shall call intense-produced when six "three quart" leyden jars $C C^{\prime}$ were used on each electrode in addition to the jars with which the electric machine was equipped, and the capacity $K$ consisted of eighteen jars. A weaker wave was obtained by removing five jars from each terminal of the machine and by reducing the capacity $K$ from eighteen jars to six jars. The difference in the sound intensities in the two cases was very noticeable to the ear. The difference in the light intensities was quite marked. With the heavier discharge a ten-minute tank development of the dry plate gave a much denser negative than a thirty-minute development in the case of the lighter discharge.

To show at a glance just what has happened I have drawn on Fig. 2 a broken line circle with the sound gap as center. To avoid confusion the circle is drawn just outside the free wave. It will be noted that the waves through the tubes lie well outside the circle, showing that their speed is greater than the speed of the wave in free air, and that the speeds of the waves through the four tubes are apparently the same, although the tube diameters are in the approximate ratios of $\mathrm{I}, 2,3$ and 5 .

Fig. 3 was obtained by replacing the four short tubes by two longer ones of 0.25 and $1.15 \mathrm{~cm}$. internal diameter, respectively, each $10 \mathrm{~cm}$. long, and adjusted radially as in Fig. 2. The ends of the two tubes included but half the length of the sound gap, so that the other end of the cylindrical wave traveled outward in free air. It will be noted that here again we have a greater speed through the tubes than in free air, and what is more, that the speed through the smaller tube is the greater.

On the original negative from which Plate $I$. is a reduced print, the

${ }^{1}$ Physical Review, V. 35, p. 373, I912; Proc. Indiana Acad. Sci., p. 305, I91 5. 


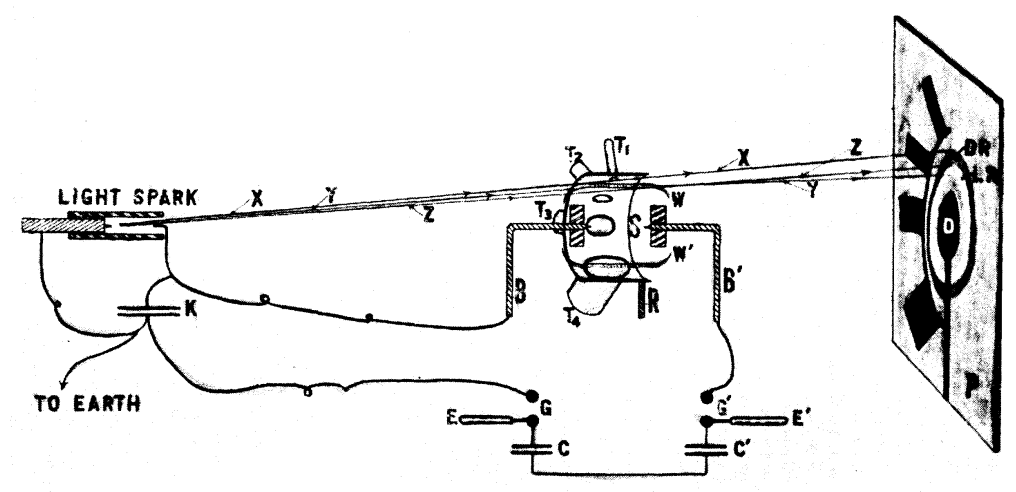

FIG. I.

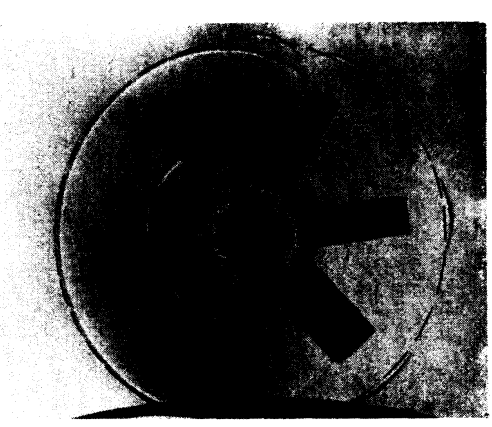

Fig. 2 .

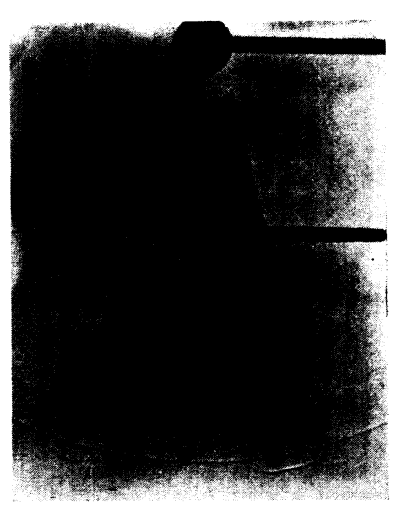

FIG. 3.

ARTHUR L. FOLEY. 
tube shadow is $4.56 \mathrm{~cm}$. long and the tube wave $0.48 \mathrm{~cm}$. in advance of the free wave. Assuming the entire gain in space traversed occurred while the wave was inside the tube, an assumption which I think is not altogether true, the relative increase in speed is the ratio of 0.48 to $4.5^{6}$, or 10.5 per cent. In the case of Fig. 3 the shadow length is $16.5 \mathrm{~cm}$. and the gain of the wave in the smaller tube $.89 \mathrm{~cm}$., corresponding to a speed increase of 5.4 per cent. Comparing Figs. 2 and 3, it would appear that more than half the gain was made in the first fourth of the tube's length, and that if the tube were long enough the speed might drop to the values obtained by other experimenters, or even below-for their results are averages through tubes of considerable length.

The writer makes the above calculations merely as an illustration of what occurred in the case of Figs. 2 and 3, and not because he attaches any significance whatever to the values given. As a matter of fact they have no significance. The writer has photographs which show sound waves through pipes all the way from twenty per cent. behind to twenty per cent. ahead of the portions of the wave that traveled in free air. The speed is chiefly a question of the intensity of the wave as it enters the pipe. In the space near a sound source the intensity of a yave decreases very rapidly with increase in distance. Inside a pipe a wave can not spread out and so its intensity, if the pipe is smooth and rigid-walled, varies slowly. If, then, the end of a short pipe is near a sound source, such as an electric spark, the average intensity of the portion of the wave inside the pipe is greater than the average intensity of the wave outside, and the former, therefore, moves the faster. The writer tested this conclusion in several different ways, a few of which will be given.

I. An intense spark gave a greater difference between the speed in tubes and free air than a weak spark, particularly in the case of long tubes.

2. Pictures of waves through tubes varying from $2.5 \mathrm{~cm}$. to $20 \mathrm{~cm}$. in length showed that the tube speed was greater at first than the free air speed, but that it gradually decreased and eventually became less than the free air speed. An attempt to photograph waves at different points inside the tubes failed. Neither glass nor transparent quartz tubes would transmit enough light from the illuminating spark to affect a dry plate.

3. When two tubes of the same diameter and length were placed radially to the sound gap and with their ends near and at the same distance from the gap, each of the tube waves showed the same gain over the free air wave. When one of the tubes was moved radially toward the spark so that the intensity of the wave entering it was greater 
than the intensity of the wave entering the other tube, the wave through the former gained on the wave through the latter. When both tubes were moved away from the gap the gain in each was correspondingly decreased. At a distance of two to five centimeters, depending on the intensity of the spark and to a less extent upon the size of the tube, the tube speed became less than the free air speed.

4. Two tubes, each $20 \mathrm{~cm}$. long, were soldered together side by side and one sawed in two, crosswise, near the middle, making a cut about $2 \mathrm{~mm}$. wide. When a wave passed the cut a part of its energy was lost and the wave emerged from the far end of the divided tube behind the wave through the continuous tube.

5 . When a thin membrane of collodion, as used in making the lenses described in a former paper, was stretched across the end of a tube the wave speed through the tube was diminished. The decrease was greater when the membrane was on the end of the tube next the sound spark, than it was when placed on the far end. This result is readily explained when one considers the twofold effect of a membrane closing the end of a tube. In the first place, it either entirely or partially prevents the air in the tube moving bodily, depending respectively on whether the membrane is on the end of the tube next to or farthest from the sound spark. In the second place, if the membrane is placed next the spark so much of the wave energy is reflected at its surface that the intensity of the wave through the tube is greatly diminished. Inasmuch as the writer obtained photographs when the membrane was next the spark gap showing wave speeds greater for intense than for weak sparks, it is clear that Rink and others are wrong in their contention that sound speeds above normal are necessarily to be attributed to a motion of the air in a body.

While the speeds determined in this investigation are relative only, the experiment establishes the following conclusions:

I. The speed of a sound pulse in a short pipe may be greater than the same pulse in free air, and it may be greater in a small pipe than in a large one.

2. The speed of a sound pulse in a pipe depends on the intensity of the pulse as it enters the pipe rather than upon the intensity of the sound source.

3. The speed of a spark wave through a pipe may be increased by the motion of the air in a body, but strong sparks give an increased wave speed near the spark, even when such motion is prevented.

4. The speed of sound in tubes can not be represented by the Helmholtz equation or by any other equation which is independent of intensity.

5. Accurate determination of the speed of a traveling wave can not 
be obtained by measuring wave lengths and frequencies of standing waves.

In a paper to be published soon the writer will describe an experiment in which he has measured the absolute speed of sound by a photographic method.

WATERMAN INSTITUTE FOR RESEARCH,

INDIANA UNIVERSITY,

March, I9I9. 


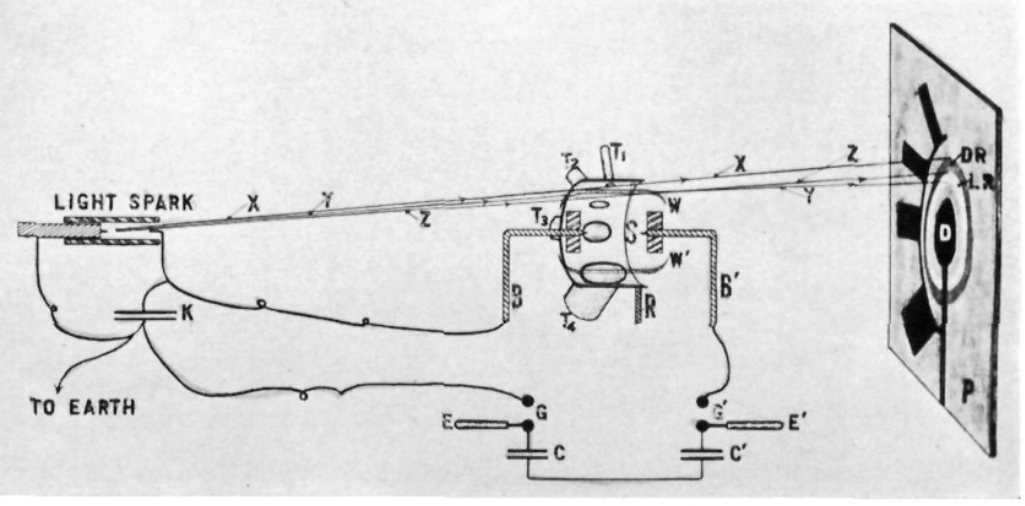

FIG. I. 


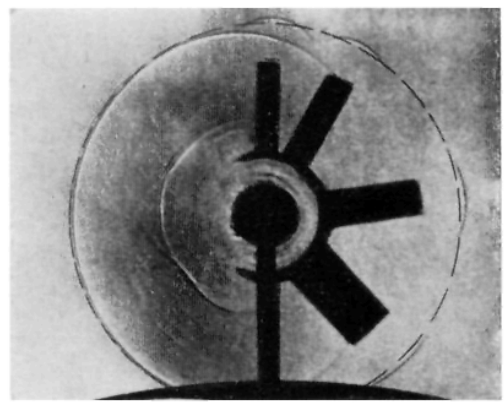

FIG. 2. 


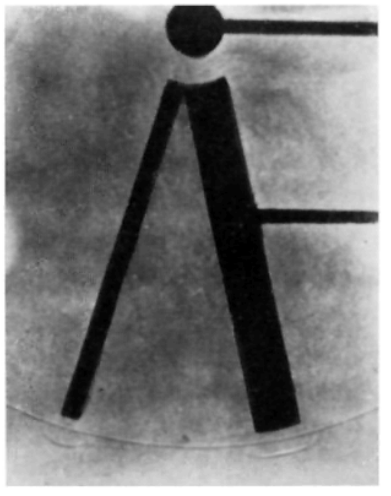

FIG. 3. 